\title{
Monosomy for the most telomeric, gene-rich region of the short arm of human chromosome 16 causes minimal phenotypic effects
}

\author{
Sharon W Horsley ${ }^{1,7}$, Rachael J Daniels ${ }^{1,7}$, Eduardo Anguita ${ }^{1}$, Helen A Raynham ${ }^{1}$, \\ John F Peden ${ }^{1}$, Ana Villegas ${ }^{2}$, Mark A Vickers ${ }^{3}$, Sarah Green ${ }^{4}$, John S Waye ${ }^{5}$, \\ David HK Chui ${ }^{5}$, Helena Ayyub ${ }^{1}$, Angela B MacCarthy ${ }^{1}$, Veronica J Buckle ${ }^{1}$, \\ Richard J Gibbons ${ }^{6}$, Lyndal Kearney ${ }^{1}$ and Douglas R Higgs*,1
}

\begin{abstract}
${ }^{1}$ MRC Molecular Haematology Unit, Institute of Molecular Medicine, John Radcliffe Hospital, Headington, Oxford OX3 9DS, UK; ${ }^{2}$ Hospital Clinico San Carlos, 28040, Madrid, Spain; ${ }^{3}$ Aberdeen Royal Infirmary, Aberdeen, AB25 2ZN, UK; ${ }^{4}$ Princess Margaret Hospital, Swindon, Wiltshire, SN1 4JU, UK; ${ }^{5}$ Department of Pathology and Molecular Medicine, McMaster University Faculty of Health Sciences, Hamilton, Ontario L8N 3Z5, Canada; ${ }^{6}$ Nuffield Department of Clinical Laboratory Sciences, University of Oxford, John Radcliffe Hospital, Headington, Oxford OX3 9DU, UK
\end{abstract}

We have examined the phenotypic effects of 21 independent deletions from the fully sequenced and annotated $356 \mathrm{~kb}$ telomeric region of the short arm of chromosome 16 (16p13.3). Fifteen genes contained within this region have been highly conserved throughout evolution and encode proteins involved in important housekeeping functions, synthesis of haemoglobin, signalling pathways and critical developmental pathways. Although a priori many of these genes would be considered candidates for critical haploinsufficient genes, none of the deletions within the $\mathbf{3 5 6} \mathbf{~ k b}$ interval cause any discernible phenotype other than $\alpha$ thalassaemia whether inherited via the maternal or paternal line. These findings contrast with previous observations on patients with larger $(>1 \mathrm{Mb})$ deletions from the $16 \mathrm{p}$ telomere and therefore address the mechanisms by which monosomy gives rise to human genetic disease. European Journal of Human Genetics (2001) 9, 217-225.

Keywords: Chromosome 16, band 16p13.3; monosomy; haploinsufficiency; AXIN1; ATR-16; alpha globin

\section{Introduction}

As the resolution of genome analysis has steadily improved over the past 20 years, an ever increasing number of human genetic diseases resulting from the loss of specific chromosomal segments has been recognised. Although some of these syndromes result from the accumulated loss of several genes, ${ }^{1}$ other complex phenotypes may result from the loss

*Correspondence: DR Higgs, MRC Molecular Haematology Unit, Institute of Molecular Medicine, John Radcliffe Hospital, Headington, Oxford OX3 9DS, UK. Tel: +44 1865222 393; Fax: +44 1865222500

E-mail: drhiggs@molbiol.ox.ac.uk

${ }^{7}$ These authors contributed equally to this work.

Received 13 September 2000; revised 13 November 2000; accepted 16 November 2000 of a single haploinsufficient gene. ${ }^{2}$ Identification of such critical gene(s) within a segment of the genome, defined by a series of deletions in patients with a particular phenotype, may be confounded by a number of factors such as chromosomal position effects, ${ }^{3}$ parental imprinting ${ }^{4}$ and genetic background. ${ }^{5}$ Therefore it will be important to establish some guidelines that might help to identify likely candidates for critical, haploinsufficient genes. To date, relatively few genes of this type have been identified; nevertheless, provisional observations have highlighted those encoding proteins that are expressed at high levels, those that form multimeric complexes and those known to be involved in the early stages of developmental pathways. ${ }^{6,7}$

We have previously identified individuals with $\alpha$ thalassaemia and a variety of developmental abnormalities, including 
mild to moderate mental retardation and facial dysmorphism with deletions involving the terminal $2 \mathrm{Mb}$ of $16 \mathrm{p} 13.3$ (ATR16 syndrome; OMIM 141750, [http://www3.ncbi.nlm.nih. gov/omim]). Although many of these cases are complicated by additional aneuploidy, ${ }^{8-10}$ others have pure monosomy for the terminal region of $16 \mathrm{p} .{ }^{11}$ In all such cases the presence of $\alpha$ thalassaemia is simply explained by haploinsufficiency for the $\alpha$ globin genes. However, it is not clear which gene(s) are responsible for the associated developmental abnormalities.

We recently sequenced and characterised all of the genes within the terminal $284 \mathrm{~kb}$ of $16 \mathrm{p} 13.3 .^{12}$ Here we have extended this analysis to $356 \mathrm{~kb}$ of the $16 \mathrm{p}$ telomere to study the effect of 21 deletions (not including the common inherited forms of $\alpha$ thalassaemia). The deletions range from $2.7-268 \mathrm{~kb}$ deleting from $1-15$ genes from this region. All of the patients were originally identified because they have $\alpha$ thalassaemia and pure monosomy for the terminal region of human chromosome $16 \mathrm{p}$. Although most of the genes in this region have been highly conserved throughout evolution and are known to be involved in a variety of important housekeeping functions, signalling pathways and critical developmental pathways, somewhat surprisingly, none of the deletions causes any discernible phenotype other than $\alpha$ thalassaemia. These findings contrast with the effects of larger deletions $(>1 \mathrm{Mb}$ ) from the $16 \mathrm{p} 13.3$ region. 9,11

\section{Materials and methods}

\section{Haematological analysis}

All haematological studies, including the analysis of haemoglobin and identification of haemoglobin $\mathrm{H}$ inclusions were performed using standard techniques. ${ }^{13}$

\section{FISH analysis and telomere assay to localise the deletion breakpoints}

Fluorescence in situ hybridisation (FISH) was carried out as previously described. ${ }^{14}$ The telomere assay was performed as described previously. ${ }^{15}$

\section{Characterisation of deletion breakpoints}

Deletion breakpoints were characterised by combinations of Southern blot, PCR analysis and sequence analysis. The centromeric breakpoint of the patient JT was first mapped by FISH. A human/mouse hybrid cell line was established as previously described, ${ }^{16}$ containing the abnormal chromosome 16 from patient JT as the only human chromosome. Using DNA from his hybrid, the 3' breakpoint was further mapped along the cosmid c419C1 by PCR using Qiagen ${ }^{\circledR}$ Taq PCR core kit with the primers: c419C1.1F, c419C1.1R, c419C1.2F, c419C1.2R, c419C1.3R, c419C1.4F, c419C1.4R, c419C1.5F, c419C1.5R, c419C1.7F, c419C1.7R, c419C1.8F, c 419C1.9F, c419C1.10F, c419C1.11F, c419C1.11R, c419C1.13F. The primer sequences can be accessed from the URL: http://www.molbiol.ox.ax.uk/ haem/Table2.html. The
JT DNA was also mapped by Southern blot after digestion with the restriction enzymes BfaI, ApaLI, BglII and Pst that cut close to the breakpoint area and hybridising with a PCR probe made with primers c419C1.7R and c419C1.12F.

Ten micrograms of DNA were digested with the enzyme $B f a I$. The DNA was subsequently de-proteinised, phenol extracted and precipitated with ethanol. The DNA was circularised, amplified by inverse $\mathrm{PCR}^{17-19}$ with primers c419C1.10F and c419C1.9R and the product reamplified by hemi nested PCR with internal primers c419C1.8F and c419C1.7F. The product of this PCR was sequenced using primer c419C1.7F.

JT hybrid DNA was amplified with primers cNFG9.13F from the cNFG9 cosmid sequence and c419C1.9R, cNFG9.13Fc419C1.11R and cNFG9.13F- c419C1.7R, and the products sequenced.

\section{Results}

Extending the analysis of $16 \mathrm{p} 13.3$

We have previously characterised the genes lying within the terminal $284 \mathrm{~kb}$ of $16 \mathrm{p} 13.3 .^{12}$ Here we have extended this sequence analysis to include the terminal $356 \mathrm{~kb}$ and updated the annotation of the entire sequence localising two additional genes (3.1 and 17.1 in Figure 1 and Table 1). Public genetic sequence databases were searched with either the known or predicted protein sequences corresponding to each gene. In this way orthologues (related by direct descent from the ancestral gene) or paralogues (related indirectly via duplication of the ancestral gene) corresponding to each gene were identified in commonly studied model organisms (summarised in Figure 1 and legend). To identify abnormal phenotypes associated with all types of mutation in these genes and their relatives, we searched a variety of databases (OMIM, Flybase [http://flybase.bio.indiana.edu:82], Wormbase [http://wormbase.org], WormPD and YPD [http:// www.proteome.com]) cataloguing such mutations. This revealed few examples of abnormal phenotypes associated with mutations of these genes, probably due to the paucity of data currently available in these databases. However, in Saccharomyces cerevisiae, lethal phenotypes were observed for deletion of gene 3.1 (POLR3K, a subunit of RNA Pol III, ${ }^{20}$ ) and gene 16 (a gene related to the yeast gene LUC7, a component of the U1 snRNP complex, ${ }^{21}$ ). Nullisomy for the $\alpha$ globin genes is known to cause late foetal lethality in man and mouse ${ }^{22,23}$ and nullisomy for AXIN1 (see below) causes death in $\mathrm{d} 8$-d10 mouse embryos. ${ }^{24}$

\section{Identification of patients with monosomy for the terminal region of $16 \mathrm{p} 13.3$}

In all of the patients described here and many of those previously reported (summarised in Table 2), the initial indication that they had monosomy for $16 \mathrm{p} 13.3$ was that they had the haematological phenotype of $\alpha$ thalassaemia (Table 2 and legend) resulting from the deletion of both $\alpha$ 


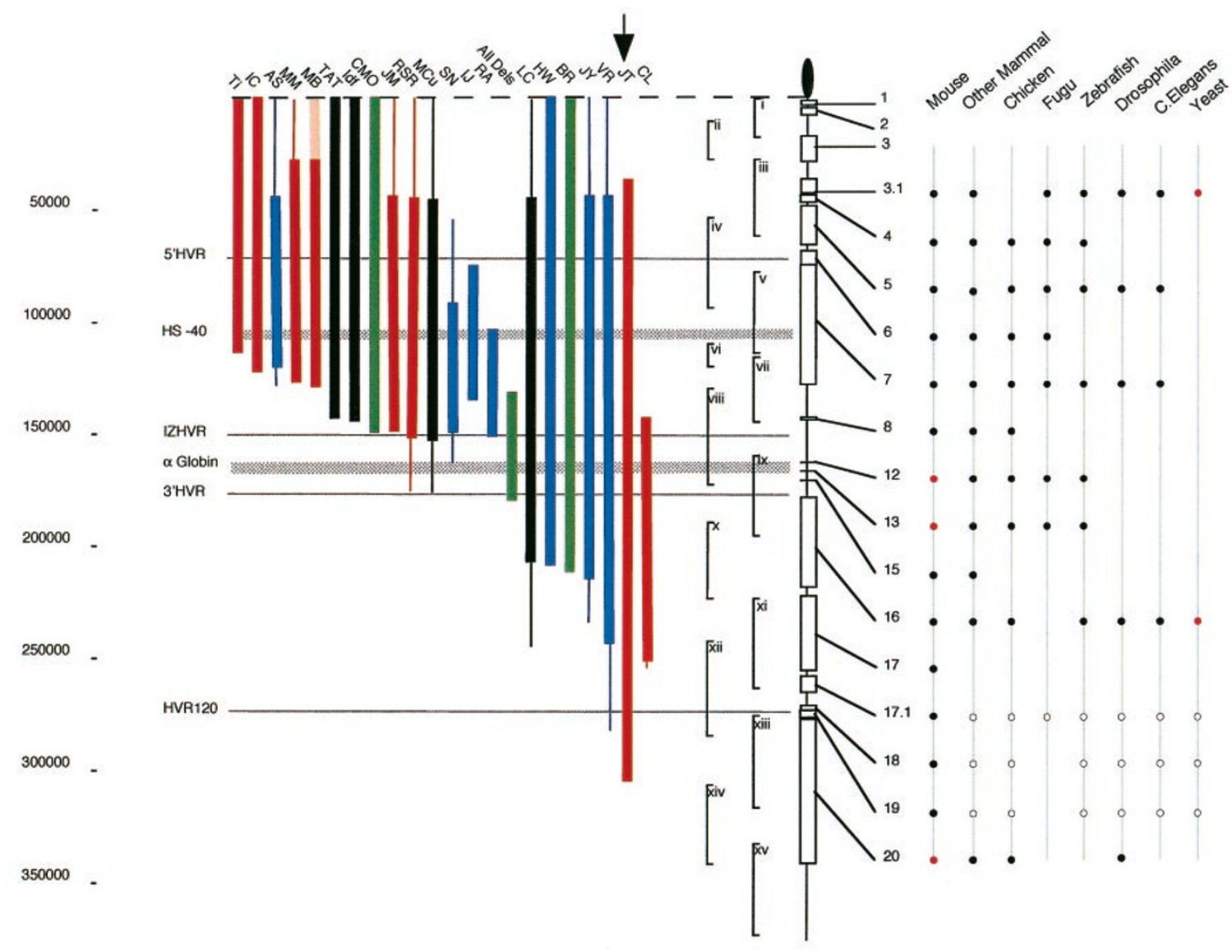

Figure 1 Summary of the structure of $16 \mathrm{p} 13.3$ and deletions within this region. The contig was generated from the following clones: $\mathrm{i}$ pTEL, ii $\lambda$ AW2, iii cNFG9, iv cRA36, v cGG4, vi pX9.4, vii c24F8, viii cGG1, ix cos12, x cRJ14, xi c310H5, xii c314G4, xiii c419C1, xiv C333B10, xv c415C1. Deletions are indicated by a solid line inherited maternally (red), paternally (blue), from either parent (green) or not determined (black). The telomeric repeat array is indicated by a solid oval and the genes are shown as open boxes (details in Table 1). The position of the VNTR loci 5'HVR, IZHVR, 3'HVR and HVR120 are indicated. The positions of HS-40 and the $\alpha$ globin genes are shown (stippled lines). A putative paralogue (open circle) and orthologue (filled circle) was identified by sequence identity in a reference organism, ie Mouse, other mammal (including Rat), Chicken, Fugu species, Zebrafish, Drosophila melanogaster, C. elegans or Yeast (S. cerevisiae or S. pombe). Where a mutation of a gene has been shown to result in a detectable phenotype, this is indicated by a red circle. A gene was putatively identified as an orthologue of a human gene if there was a reciprocal best match in both species. Where a gene had significant sequence identity to two or more genes in either species and an orthologue could not be unambiguously identified, the gene was classified as a paralogue. This information can be accessed from the URL: http://www.molbiol.ox.ax.uk/ haem/Table1.html.

globin genes from one copy of chromosome 16 (genotype $--/ \alpha \alpha$ or $--/-\alpha$, rather than the normal $\alpha \alpha / \alpha \alpha)$ or deletion of the $\alpha$ globin regulatory element $\{$ denoted $(\alpha \alpha)\}$ and the genotypes $--/ \alpha \alpha$ or $-\alpha / \alpha \alpha$, as summarised in Table 2 . Although some of them originate from areas of the world where the inherited forms of $\alpha$ thalassaemia are common, ${ }^{22}$ many come from outside of these regions and consequently the presence of $\alpha$ thalassaemia was unexpected. These patients had no other clinical abnormalities. Patient JT who has the largest deletion $(268 \mathrm{~kb})$ in this group of patients (see below) is of normal intelligence (a university graduate), has no dysmorphism and appeared phenotypically normal in all other respects (also see Discussion). $\alpha$ Thalassaemia was first diagnosed in this patient in a late stage of her first pregnancy, aged 30 years.

\section{Evaluation of chromosomal abnormality by FISH analysis}

FISH analysis was carried out on metaphase chromosomes from either peripheral blood or EBV-transformed cell lines from newly diagnosed individuals with $\alpha$ thalassaemia using cosmids and plasmids from the $16 \mathrm{p}$ contig ( $\mathrm{i}-\mathrm{xv}$ in Figure 1 ). In all cases there was a deletion of part of $16 \mathrm{p} 13.3$ and the breakpoints could be localised within one cosmid (eg VR) or between two cosmids (eg JT) summarised in Table 3. When sufficient chromosomal material was available (6/10 cases), a previously reported telomere assay ${ }^{15}$ was carried out to identify subtelomeric chromosome translocations. All patients studied in this way appeared to have simple deletions of $16 \mathrm{p} 13.3$ with no other chromosomes involved. 
Table 1 Summary of genes within $16 \mathrm{p} 13.3$

\begin{tabular}{|c|c|c|}
\hline Gene no* & Gene name & Known or possible function \\
\hline 1 & DDX11P & helicase pseudogene \\
\hline 2 & $16 p H Q G 2$ & related to CXYORF1 \\
\hline 3 & IL9RP3 & interleukin 9 receptor pseudogene \\
\hline 3.1 & POLR3K & RNA polymerase III Cii subunit protein allows RNP3 to switch between RNA elongation and RNA cleavage mode \\
\hline 4 & C16orf33 & unknown \\
\hline 5 & C16orf8 & possible role in signal transduction \\
\hline 6 & MPG & $\begin{array}{l}\text { N-methylpurine-DNA glycosylase removes a diverse group of damaged bases from DNA, including cytotoxic and } \\
\text { mutagenic alkylation adducts of purines }\end{array}$ \\
\hline 7 & C16orf35 & unknown \\
\hline 8 & $H B Z$ & zeta globin is involved in oxygen transport in embryonic life \\
\hline 9 & $H B Z P$ & zeta globin pseudogene \\
\hline 10 & HBAP2 & alpha globin pseudogene \\
\hline 11 & HBAP1 & alpha globin pseudogene \\
\hline 12 & $H B A 2$ & alpha globin 2 is involved in the production of haemoglobin and the transport of oxygen \\
\hline 13 & $H B A 1$ & alpha globin 1 is involved in the production of haemoglobin and the transport of oxygen \\
\hline 14 & ROP & HUMCRHY3 scRNA psuedogene \\
\hline 15 & HBQ1 & theta globin 1 ; possible role in early erythroid tissue \\
\hline 16 & $L U C 7 L$ & possibly an RNA binding protein \\
\hline 17 & C16orf9 & unknown \\
\hline 17.1 & RGS11 & regulator of $G$ protein signalling; negatively regulates $G$ protein signalling pathway \\
\hline 18 & ARHGDIG & rho GDP-dissociation inhibitor (GDI) gamma; prevents diassociation of GDP from Rho proteins \\
\hline 19 & PDIP & protein disulphide isomerase precursor; possibly involved in formation of secretory proteins \\
\hline 20 & AXIN1 & inhibits further axis formation in embryo once the main dorsal-ventral axis has formed \\
\hline
\end{tabular}

${ }^{*}$ Genes are as described in; ${ }^{12}$ in addition to $3.1^{20}$ and $17.1 .{ }^{47}$

Table 2 Haematological and genotyping data

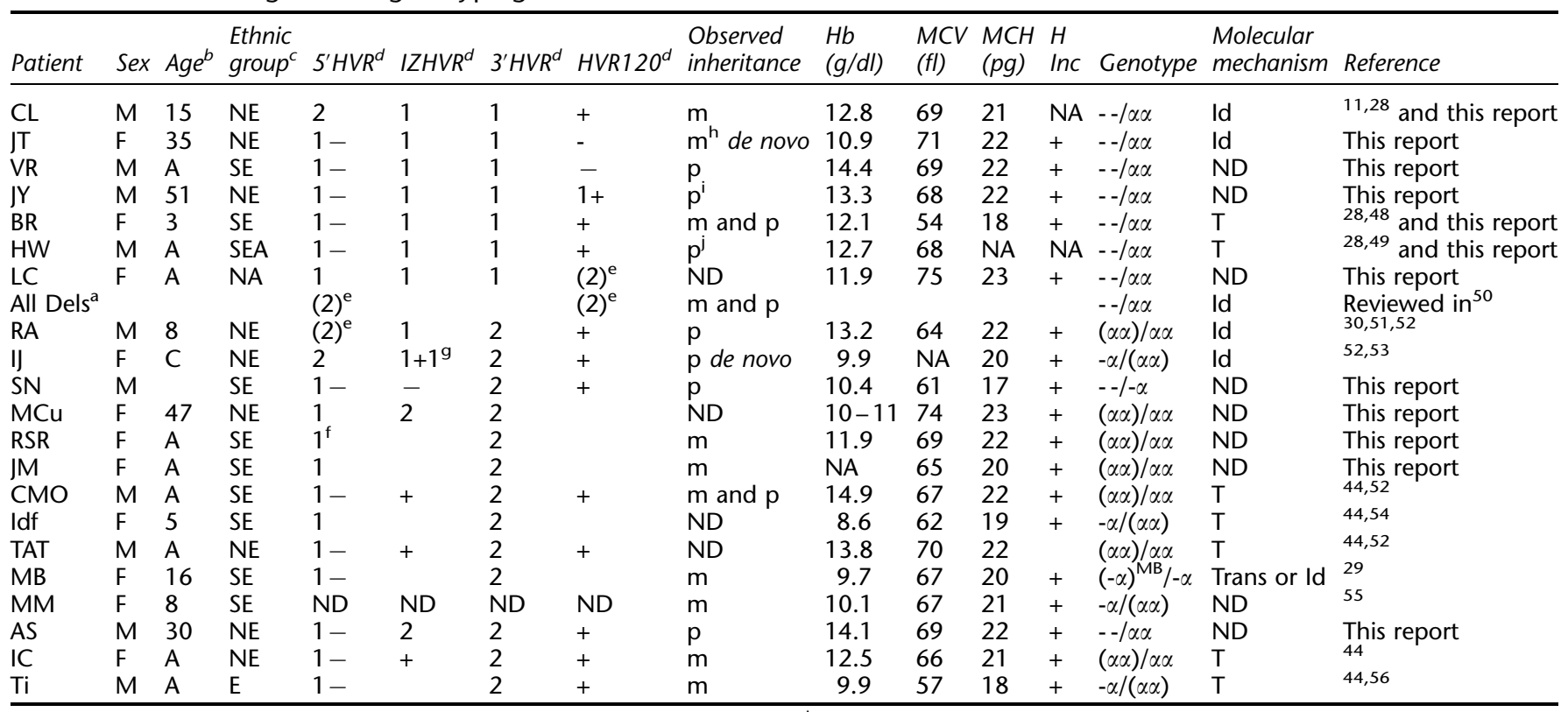

${ }^{a}$ All Dels=previously reported common deletions causing $\alpha$ thalassaemia. ${ }^{b} \mathrm{~A}=$ Adult age unspecified. ${ }^{\mathrm{c} N E}=$ North European; $\mathrm{SE}=\mathrm{South}$ European; $\mathrm{SEA}=$ Southeast Asian. ${ }_{+}{ }_{+}=$probe identifies an abnormal PFGE fragment; $-=$probe does not identify an abnormal PFGE fragment. ${ }^{e}(2)=2$ alleles must be present based on other data but not directly observed. fabsent by FISH (see Table 3). ${ }^{9} 1+1=$ the alleles are present but undistinguishable. ${ }^{h}$ Neither parent had $\alpha$ thalassaemia which therefore suggests a de novo deletion, a phenotypically normal girl inherited this mutation from her mother. ${ }^{i}$ A son inherited this mutation from his father (JY) and had Becker Muscular Dystrophy and a high grade nonHodgkin's lymphoma. The relationship of these abnormalities to the $16 \mathrm{p}$ deletion are not clear. 'Propositus had Hb Bart's hydrops fetalis due to $\alpha$ thalassaemia. $\mathrm{Hb}=$ haemoglobin; $\mathrm{MCV}=$ mean cell volume; $\mathrm{MCH}=$ mean cell haemoglobin; $\mathrm{H}$ inc=haemoglobin $\mathrm{H}$ inclusions; Id=interstitial deletion; T=chromosomal truncation; Trans=chromosomal translocations; NA=not available; ND=not determined. 
Table 3 FISH data indicating the extents of deletions

\begin{tabular}{|c|c|c|c|c|c|c|c|c|c|c|}
\hline \multirow[b]{2}{*}{ Patient } & \multicolumn{9}{|c|}{ Cosmids } & \multirow{2}{*}{$\begin{array}{l}\text { Telomer } \\
\text { assay }\end{array}$} \\
\hline & iii & iv & $v$ & viii & $i x$ & $x$ & $x i$ & $x i i$ & xiii & \\
\hline JT & - & & - & - & - & & - & - & + & $\mathrm{N}$ \\
\hline VR & - & & - & - & - & & - & \pm & + & $\mathrm{N}$ \\
\hline $\mathrm{JY}$ & - & & - & - & & - & + & & + & $\mathrm{N}$ \\
\hline HW & & & & & - & \pm & & & & ND \\
\hline LC & - & & - & - & & - & + & & & ND \\
\hline $\mathrm{MCu}$ & + & - & - & + & & & & & & ND \\
\hline RSR & - & & - & + & & & & & & $\mathrm{N}$ \\
\hline JM & - & & - & + & & & & & & $\mathrm{N}$ \\
\hline MB & & - & - & + & & & & & & ND \\
\hline AS & - & & - & + & & & & & & $\mathrm{N}$ \\
\hline
\end{tabular}

- , probe absent; +, probe present; \pm , probe had a reduced FISH signal, possibly indicating that the breakpoint lies within this cosmid. Blanks indicate FISH was not performed using this cosmid. The far right hand column indicates those patients who were analysed for subtelomeric rearrangements using the telomere assay. $\mathrm{N}$, no rearrangement; ND, not done.

Molecular analysis of deletions within $16 \mathrm{p} 13.3$

Preliminary evaluation of the extent of each deletion was assessed by scoring the number of alleles at the polymorphic, variable number of tandem repeat (VNTR) loci 5'HVR, IZHVR, 3'HVR and HVR120 $25-28$ in the terminal region of $16 \mathrm{p} 13.3$ (Figure 1 and Table 2). In many cases, the presence or absence of these and other probes (available on request) was also assessed by whether or not they identified abnormal restriction fragments on Southern blots after pulsed field gel electrophoresis (PFGE, data not shown). Breakpoints were further localised to different degrees of resolution (Figure 1) by conventional Southern blotting, PFGE and PCR assays (see Materials and methods). In some cases (CL, BR, HW and JT) the breakpoint was cloned and localised precisely by mapping and/or DNA sequence analysis (eg see Figure 2).

In each affected family, where possible, we established whether the abnormal chromosome had been inherited or passed on to an individual with $\alpha$ thalassaemia via the maternal or paternal line (Figure 1 and Table 2). In this way it was possible to investigate whether some segments of the terminal region of $16 \mathrm{p} 13.3$ might be parentally imprinted. However, no differences were seen between patients that inherited a monosomic segment from either parent.

\section{Characterisation of the mechanisms involved in} deletions of $16 \mathrm{p} 13.3$

We have previously characterised the mechanisms by which many deletions have occurred in 16p13.3 (summarised in Table 2); these include subtelomeric translocation, ${ }^{8}$ truncation and healing with telomeric repeats, ${ }^{11}$ interstitial deletions due to misaligned homologous recombination ${ }^{29}$ and illegitimate recombination. ${ }^{30}$ Using previously reported approaches, we demonstrated two additional examples (BR and $\mathrm{HW}$ ) of chromosome truncation and healing with telomeric repeats (summarised in Figure 2 and legend). Since JT has the largest deletion extending through this region

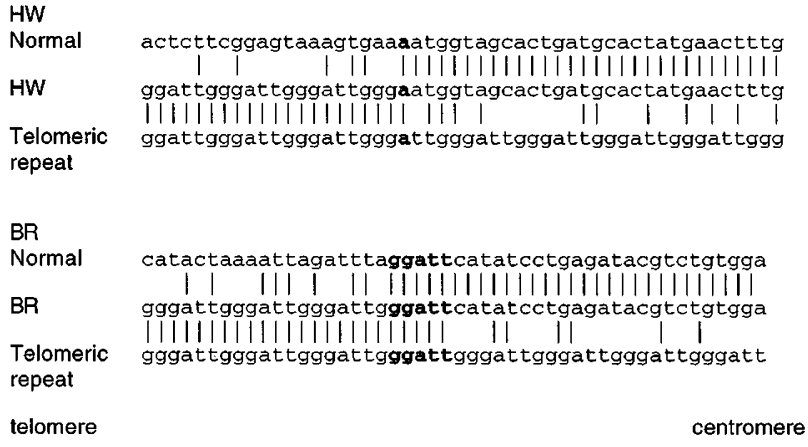

Figure 2 Characterisation of breakpoints in two patients with truncations of $16 \mathrm{p} 13.3$. The deletions in HW and BR were delimited using the probe pNFG400 43 and the HVRs described in Table 2 in family studies. In addition, interspecific hybrids containing the abnormal HW and BR chromosomes were analysed by conventional or PFGE Southern blots. As previously described for other chromosome truncations, ${ }^{44}$ fragments spanning the breakpoint were heterogeneous in size producing 'smears' on Southern blots rather than discrete fragments. PCR products across the breakpoints were cloned into Smal cut puc 18 as previously described ${ }^{44}$ and sequenced. Comparison of the truncated chromosomes with the normal chromosomal sequence revealed that both breakpoints resulted from a simple break with telomeric healing. The precise breaks could be localised to a single nucleotide in $\mathrm{HW}$ and to one of five nucleotides in BR, since a stretch of five nucleotides of the normal sequence was identical to, and in phase with the telomeric array.

$(268 \mathrm{~kb})$ and this is potentially the most informative deletion allowing us to relate a well defined segment of monosomy to phenotype, we characterised this mutation in detail.

The centromeric breakpoint was localised by FISH (Table 3) between cosmid xii (c314G4) and cosmid xiii (c419C1). This breakpoint was further localised by analysing DNA from an interspecific hybrid (JT9) containing the abnormal copy of chromosome 16 alone. Primer pairs were designed to amplify segments of genomic DNA located in c419C1 (xiii). A positive PCR indicated the segment was present, a negative PCR that the segment was deleted. Ultimately using this approach the breakpoint, confirmed by Southern blot analysis (Figure 3), was localised to a gap of 268 bp between co-ordinates 301974 and 302242 .

The breakpoint was characterised using inverse PCR. ${ }^{17-19}$ Southern blot analysis was performed using a variety of restriction enzymes that cut close to the breakpoint and the probe c419C1.7R-12F (302328-303035). Using BfaI, an abnormal fragment $(1.6 \mathrm{~kb})$ was identified (normal fragment, $1.7 \mathrm{~kb}$ ) (data not shown). DNA from the JT9 hybrid was cut with $B f a I$, circularised and ligated, and amplified by inverse PCR using the primers c419C1.10F and c419C1.9R (Figure 3). Further amplification of this product with internal primers (c419C1.7F and c419C1.8F not shown) produced a fragment of $1.1 \mathrm{~kb}$, which was sequenced. A search using this sequence 
(a)

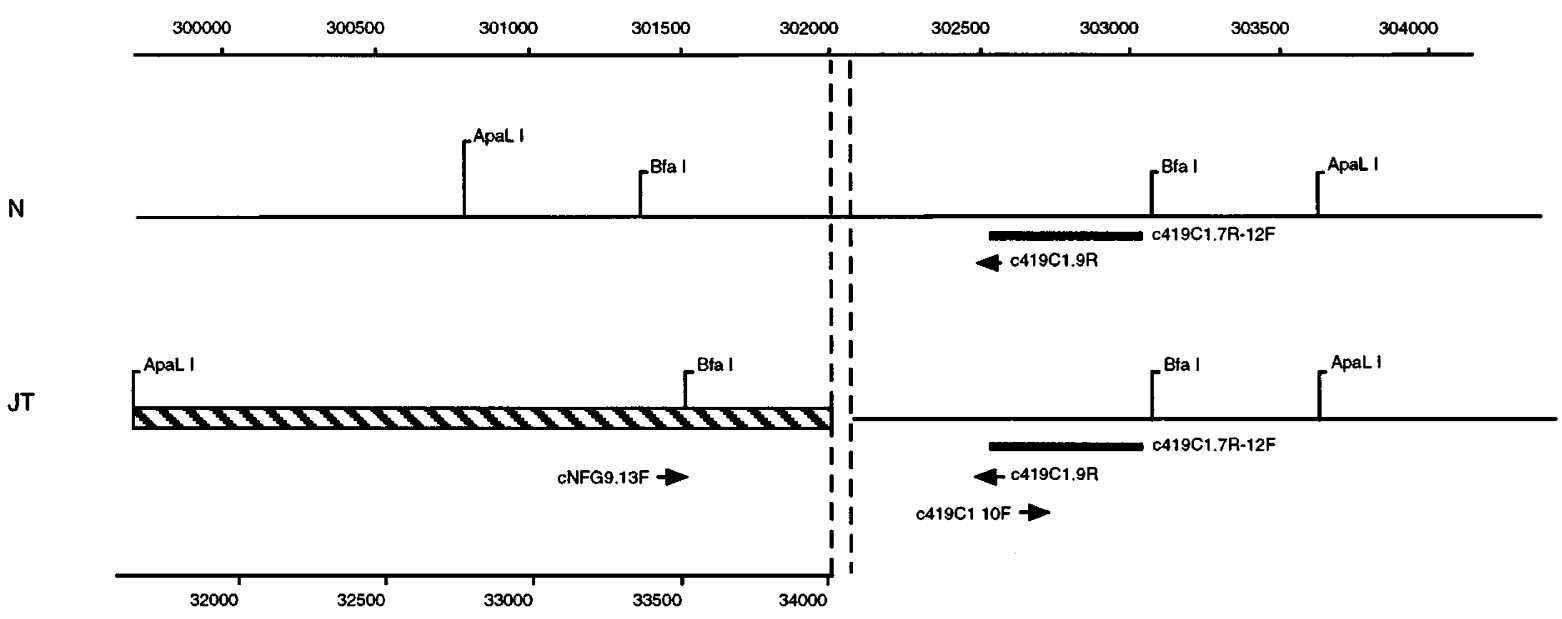

(b)

ApaL I

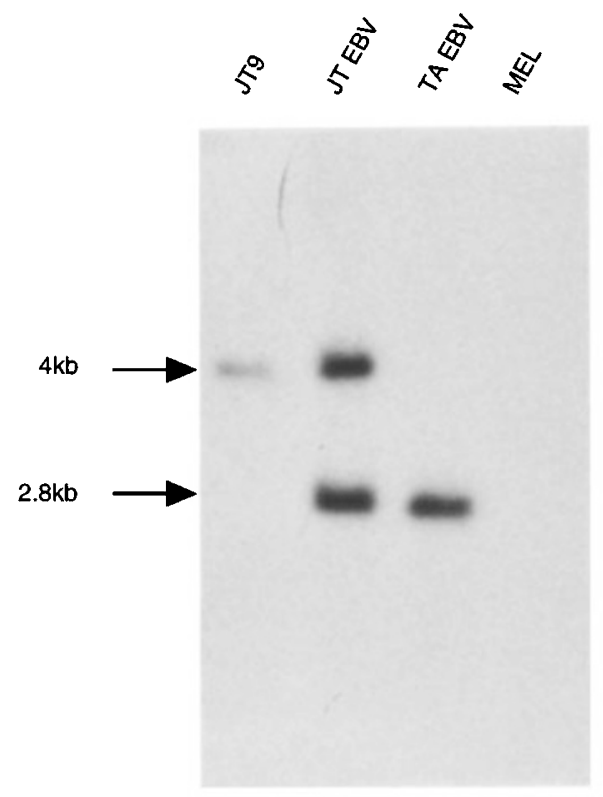

C419C1 7R-12F

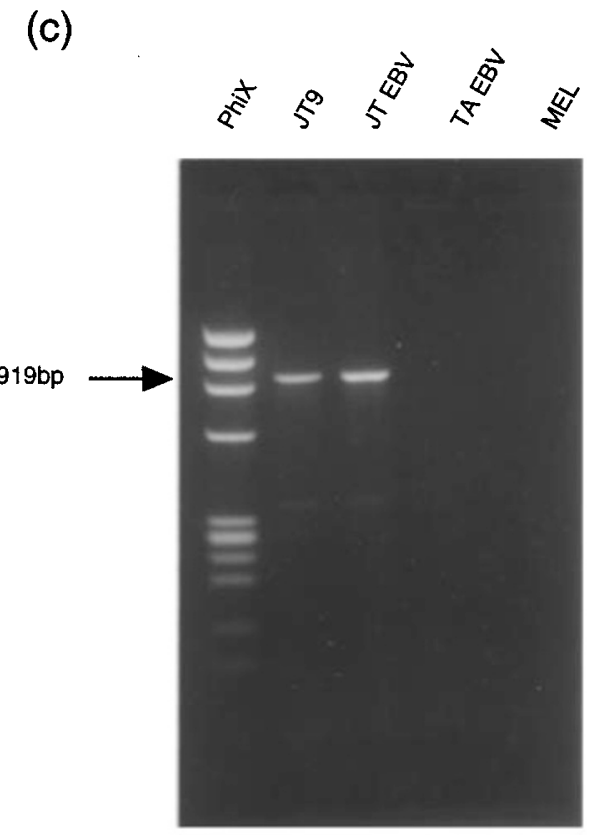

CNFG9.13F C419C1.9R

Figure 3 Characterisation of the JT breakpoints. (a) Restriction map obtained with the $\mathrm{c} 419 \mathrm{C} 1.7 \mathrm{R}-12 \mathrm{~F}$ probe (black box), used to characterise the JT breakpoint, with the enzymes Bfal and ApaLI, in a normal individual $(\mathrm{N})$ and in the patient (JT). The diagonally striped line represents CNFG9 and the thin line $c 419 \mathrm{C} 1$. Primers CNFG9.13F and C419C1.9R were used to amplify a DNA fragment across the JT breakpoint, which was subsequently sequenced. Inverse PCR was performed using primers C419C1.10F and c419C1.9R. Primers are shown beside arrows. The scale is in base pairs. (b) Southern blot using ApaLI digested DNA that shows the predicted differences between JT and a normal subject (TA). Lane 1: DNA from an interspecific hybrid containing the JT abnormal copy of chromosome 16 alone (JT9) showing a $4 \mathrm{~kb}$ band. Lane 2: JT genomic DNA with a $4 \mathrm{~kb}$ and normal $2.8 \mathrm{~kb}$ bands. Lane 3: normal human DNA showing the $2.8 \mathrm{~kb}$ band only. Lane 4: mouse erythroleukaemia cell line (MEL) DNA, used as negative control. (c) PCR performed with the primers cNFG9.13F and c419C1.9R. Lane 1: molecular weight marker ( $\phi$ X174 Haell digested DNA). Lane 2: JT9 DNA. Lane 3: JT genomic DNA (the last two lanes show a 919 bp product of amplification). Lane 4: normal subject DNA. Lane 5: MEL DNA. 
identified homologies to both c419C1 (xiii in Figure 1) and cNFG9 (iii in Figure 1) indicating that JT has an interstitial deletion with a telomeric breakpoint in cNFG9.

Using this information a new set of PCR primers were designed to determine whether 'gap PCR' could detect this putative $\sim 280 \mathrm{~kb}$ interstitial deletion. Using the primers cNFG9.13F (co-ordinate 33434) and c419C1.9R (co-ordinate 302327) a $919 \mathrm{bp}$ fragment specific for this deletion was identified (Figure 3). Further DNA sequence analysis showed that the deletion resulted from recombination between two misaligned Alu-Y repeats, the breakpoint lying between coordinates 34035-34092 and 302034-302091 (Figure 4).

\section{Discussion}

Most cytogenetically detectable chromosomal rearrangements are either lethal or associated with significant phenotypic abnormalities. This conclusion results from both ascertainment bias and from the fact that even the most sensitive cytogenetic analysis (other than FISH) will only detect chromosomal abnormalities involving substantial regions $(2-5 \mathrm{Mb})$ of a chromosome. A few cases of partial monosomy with a normal phenotype have been reported ${ }^{31-}$

${ }^{34}$ but these nearly all involve Giemsa dark bands which, in general, are thought to contain a low density of genes. A rare exception to this has been reported ${ }^{35}$ of a normal individual with a terminal deletion of the Giemsa light band 5p15.3.

Analysing well defined chromosomal deletions in the context of fully sequenced and annotated human chromo- somes will provide precise correlations between genotype and phenotype. In addition, this will allow us to accurately identify regions of the genome that are sensitive to monosomy and the mechanisms by which this affects phenotype. Conversely, it will be equally important to identify gene-rich regions that are not sensitive to monosomy so that one may build a profile of which classes of gene are sensitive to being present as a single copy. From our current knowledge, one can predict that monosomy might cause abnormalities in gene expression in one of three ways. First, it may remove the active copy of a parentally imprinted locus. ${ }^{4}$ Second, it may remove one or more haploinsufficient genes. ${ }^{1}$ Finally, and by far the least likely, monosomy may rarely unmask the effects of recessive alleles carried on the homologous chromosome. The data presented here address these issues for the most telomeric region of the short arm of chromosome 16 .

In the current study we observed no abnormal phenotypes, other than $\alpha$ thalassaemia, associated with any of the deletions $(2.7-268 \mathrm{~kb})$ whether they were inherited through the maternal or paternal line (Figure 1). This is consistent with the fact that, to date, there is no evidence that the region studied here is parentally imprinted. In the human locus, the pattern of DNAse1 hypersensitivity, ${ }^{36}$ methylation, $^{37}$ replication ${ }^{38}$ and nuclear localisation (S Amoils et al, manuscript in preparation) appears equivalent for the two $16 \mathrm{p}$ homologues in all regions tested. Furthermore, expression of stable allelic variants of the $\alpha$ globin genes is equivalent from both paternal and maternal chromosomes. ${ }^{39}$

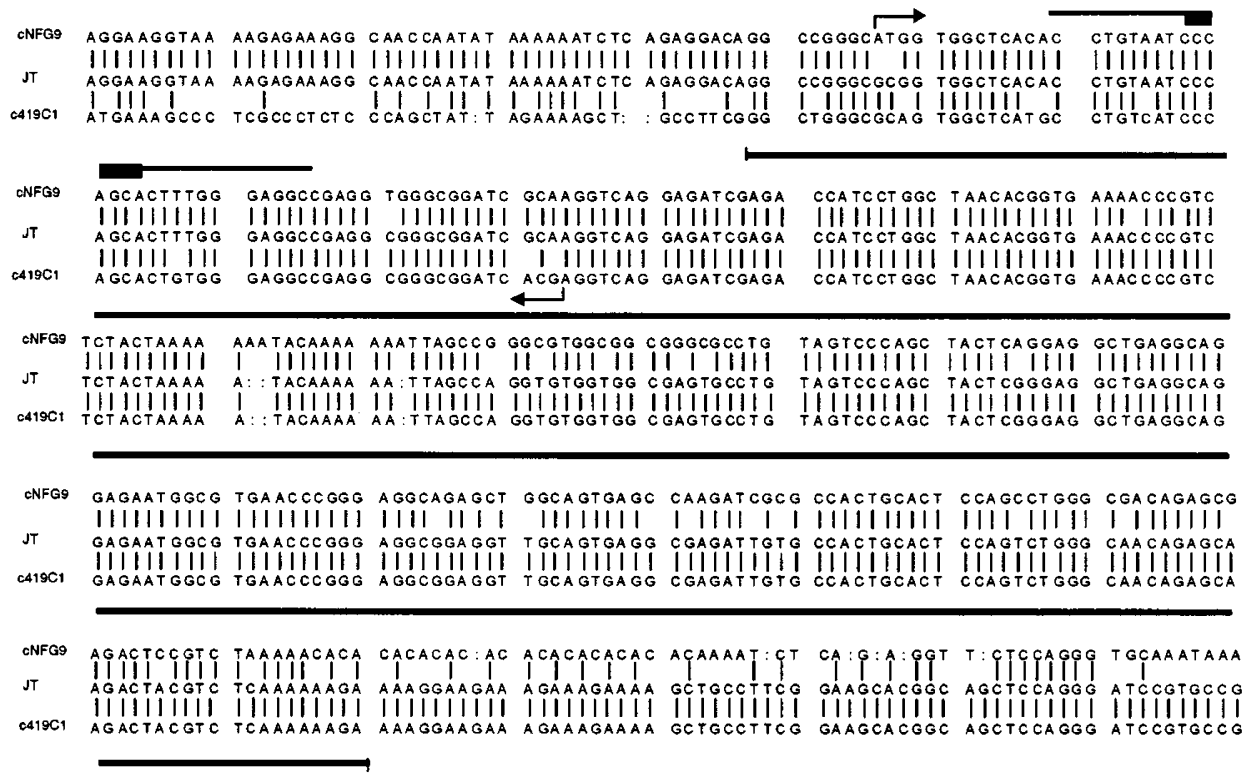

Figure 4 Sequence of the JT breakpoints. Comparison of the JT breakpoint sequence with the cosmids CNFG9 and c419C1. The recombination event occurred in the sequence delimited with arrows, within an Alu repeat (indicated by a black line beneath the sequence). Inside the recombination zone there is a $26 \mathrm{bp}$ core sequence (black line above the sequence) frequently found in other recombination events ${ }^{45,46}$ which contains the pentanucleotide motif CCAGC that is part of the Escherichia coli recombinational hotspot chi (black box). 
HS24F8 (Z69666), HSGG1 (Z84721), HScos12 (Z69706), HSRJ14 (Z69890), HS310H5 (Z69705), HS314G4 (Z69667), HS419C1 (Z99754), HS333B10 (Z81450), HS415C1 (Z98272).

\section{Acknowledgements}

We are grateful to the Chromosome 16 Project Group (Sanger Centre, Hinxton, Cambs., UK) for contributions to the sequence generated from cosmids c419C1 to c415C1. We thank E Rose for help in preparing the manuscript and Jackie Sloane-Stanley for making the hybrid cell line. We are grateful to Professor DJ Weatherall for his support and encouragement.

Of particular interest in this region is the AXIN1 (Axis inhibition) gene. It encodes the protein axin which plays a critical role in the highly conserved Wnt (Wingless/segment polarity) signalling pathway that is essential for development and organogenesis. ${ }^{40}$ One of the earliest roles for axin in development is in the formation of the embryonic axis. In mouse, nullisomy is lethal (in embryos between d8-d10) but heterozygotes for loss of function appear normal. ${ }^{41}$ Three dominant, gain-of-function mutations (Fused, Knobbly and Kinky) are associated with various abnormalities of axial structures, neural tube defects, deafness and urogenital anomalies. $^{24}$

The deletion in JT includes the last 8 exons of AXIN1 and could potentially encode a dominant negative protein. Careful evaluation of JT revealed no abnormalities in neural or intellectual development. In particular there was no clinical or X-ray evidence for abnormal development of the spine and no evidence for hearing loss using standard audiometry (data not shown). Penetrance of dominant AXIN1 mutations may depend on genetic background ${ }^{42}$ therefore it was of interest to note that her daughter, who also carries the AXIN1 mutation, is clinically normal.

A long-standing question is whether the phenotypes associated with monosomy arise from the removal of critical, haploinsufficient genes or the accumulated effects of removing many 'subcritical' genes. In this case, the more genes that are removed, the more severe the phenotype would be. While there are clear examples where removal of a single gene has a profound effect on phenotype, it will be much more difficult to test the second complementary hypothesis that, in some cases, many genes contribute to a particular syndrome associated with monosomy for a specific segment of a chromosome. Here we have shown that even in a region containing many highly conserved potentially haploinsufficient genes, indistinguishable phenotypes result from the deletion of either one or 15 genes. Further analysis of the terminal region of $16 \mathrm{p} 13.3$, when fully annotated, including patients with much larger deletions (up to $1.8 \mathrm{Mb}$ ) and abnormal phenotypes, will allow us to address this important question in further detail.

\section{Accession numbers}

HSpTEL (Z84812), HsLAW2 (Z84723), HSNFG9 (Z69719), HSRA36 (Z69720), HSGG4 (Z84722), HSX94 (Z84813),

\section{References}

1 Budarf ML, Emanuel BS: Progress in the autosomal segmental aneusomy syndromes (SASs): single or multi-locus disorders? Hum Mol Genet 1997; 6: 1657-1665.

$2 \mathrm{Li} \mathrm{L}$, Krantz ID, Deng Y et al: Alagille syndrome is caused by mutations in human Jagged1, which encodes a ligand for Notch1. Nat Genet 1997; 16: 243-251.

3 Kleinjan DJ, van Heyningen V: Position effect in human genetic disease. Hum Mol Genet 1998; 7: 1611-1618.

4 Lalande M: Parental imprinting and human disease. Annu Rev Genet 1997; 30: 173-195.

5 Ozturk IC, Killeen AA: An overview of genetic factors influencing plasma lipid levels and coronary artery disease risk. Arch Pathol Lab Med 1999; 123: 1219-1222.

6 Fisher E, Scambler P: Human haploinsufficiency-one for sorrow, two for joy. Nat Genet 1994; 7: 5 -7.

7 Wilkie AOM: The molecular basis of genetic dominance. J Med Genet 1994; 31: 89-98.

8 Lamb J, Wilkie AOM, Harris PC et al: Detection of breakpoints in submicroscopic chromosomal translocation, illustrating an important mechanism for genetic disease. Lancet 1989; 2 . $819-824$.

9 Wilkie AOM, Buckle VJ, Harris PC et al. Clinical features and molecular analysis of the $\alpha$ thalassaemia/mental retardation syndromes. I. Cases due to deletions involving chromosome band 16p13.3. Am J Hum Genet 1990; 46: 1112-1126.

10 Rack KA, Harris PC, MacCarthy AB et al: Characterization of three de novo derivative chromosomes 16 by 'reverse chromosome painting' and molecular analysis. Am J Hum Genet 1993; 52: 987 - 997.

11 Lamb J, Harris PC, Wilkie AOM, Wood WG, Dauwerse JG, Higgs DR: De novo truncation of chromosome 16p and healing with (TTAGGG) $)_{\mathrm{n}}$ in the $\alpha$-thalassemia/mental retardation syndrome (ATR-16). Am J Hum Genet 1993; 52: 668-676.

12 Flint J, Thomas K, Micklem G et al: The relationship between chromosome structure and function at a human telomeric region. Nat Genet 1997; 15: 252-257.

13 Weatherall DJ, Clegg JB: The Thalassaemia Syndromes. Oxford, Blackwell Scientific Publications, 1981.

14 Buckle VJ, Rack K: Fluorescent in situ hybridisation. in Davies KE (eds): Human genetic disease analysis: a practical approach. Oxford, Oxford University Press, 1993, vol 2, pp 59-80.

15 Knight SJL, Horsley SW, Regan R et al: Development and clinical application of an innovative fluorescence in situ hybridisation technique which detects submicroscopic rearrangements involving telomeres. Eur J Hum Genet 1997; 5: 1-8.

16 Zeitlin HC, Weatherall DJ: Selective expression within the $\alpha$ globin gene complex following chromosome dependant transfer into diploid mouse erythroleukaemia cells. Mol Biol Med 1983; 1: 489-500. 
17 Collins FS, Weissman SM: Directional cloning of DNA fragments at a large distance from an initial probe: a circularization method. Proc Natl Acad Sci USA 1984; 81: 6812-6816.

18 Ochman H, Gerber AS, Hartl DL: Genetic applications of an inverse polymerase chain reaction. Genetics 1988; 120: 621623.

19 Triglia T, Peterson MG, Kemp DJ: A procedure for in vitro amplification of DNA segments that lie outside the boundaries of known sequences. Nucleic Acids Res 1988; 16: 8186.

20 Chédin S, Riva M, Schultz P, Sentenac A, Carles C: The RNA cleavage activity of RNA polymerase III is mediated by an essential TFIIS-like subunit and is important for transcription termination. Genes Dev 1998; 12: 3857-3871.

21 Fortes P, Bilbao-Cortés D, Fornerod M et al: Luc7p, a novel yeast U1 snRNP protein with a role in $5^{\prime}$ splice site recognition. Genes Dev 1999; 13: 2425 - 2438

22 Higgs DR: $\alpha$-thalassaemia; in Higgs DR, Weatherall DJ (eds): Baillière's Clinical Haematology. International Practice and Research: The Haemoglobinopathies. London, Baillière Tindall, 1993, vol 6: pp 117-150.

23 Pászty C, Mohandas N, Stevens ME et al: Lethal alphathalassaemia created by gene targeting in mice and its genetic rescue. Nat Genet 1995; 11: 33 - 39.

24 Vasicek TJ, Zeng L, Guan XJ, Zhang T, Costantini F, Tilghman SM: Two dominant mutations in the mouse fused gene are the result of transposon insertions. Genetics 1997; 147: 777-786.

25 Goodbourn SEY, Higgs DR, Clegg JB, Weatherall DJ: Molecular basis of length polymorphism in the human $\zeta$-globin gene complex. Proc Natl Acad Sci USA 1983; 80: 5022-5026.

26 Jarman AP, Nicholls RD, Weatherall DJ, Clegg JB, Higgs DR: Molecular characterization of a hypervariable region downstream of the human $\alpha$-globin gene cluster. $E M B O ~ J$ 1986; 5: $1857-1863$.

27 Jarman AP, Higgs DR: A new hypervariable marker for the human $\alpha$-globin gene cluster. Am J Hum Genet 1988; 42: 8-16.

28 Raynham HA: The molecular basis of the ATR-16 (alpha thalassaemia/mental retardation) syndrome. University of Oxford. DPhil, 1995.

29 Flint J, Rochette J, Craddock CF et al: Chromosomal stabilisation by a subtelomeric rearrangement involving two closely related Alu elements. Hum Mol Genet 1996; 5: 1163-1169.

30 Nicholls RD, Fischel-Ghodsian N, Higgs DR: Recombination at the human $\alpha$-globin gene cluster: sequence features and topological constraints. Cell 1987; 49: 369 - 378.

31 Barber JCK, Mahl H, Portch J, Crawfurd MDA: Interstitial deletions without phenotypic effect: prenatal diagnosis of a new family and brief review. Prenat Diagn 1991; 11: 411-416.

32 Knight LA, Yong MH, Tan M, Ng ISL: Del(3) (p25.3) without phenotypic effect. J Med Genet 1995; 32: 994-995.

33 Tupler R, Berardinelli A, Barbierato L et al: Monosomy of distal $4 \mathrm{q}$ does not cause facioscapulohumeral muscular dystrophy. $J$ Med Genet 1996; 33: 366-370.

34 Kumar A, Cassidy SB, Romero L, Schwartz S: Molecular cytogenetics of a de novo interstitial deletion of chromosome arm 6q in a developmentally normal girl. Am J Med Genet 1999; 86: $227-231$.

35 Overhauser J, Huang $\mathrm{X}$, Gersh $\mathrm{M}$ et al: Molecular and phenotypic mapping of the short arm of chromosome 5: sublocalization of the critical region for the cri-du-chat syndrome. Hum Mol Genet 1994; 3: 247-252.

36 Higgs DR, Wood WG, Jarman AP et al: A major positive regulatory region located far upstream of the human $\alpha$-globin gene locus. Genes Dev 1990; 4: 1588-1601.

37 Vyas P, Vickers MA, Simmons DL, Ayyub H, Craddock CF, Higgs DR: Cis-acting sequences regulating expression of the human $\alpha$ globin cluster lie within constitutively open chromatin. Cell 1992; 69: $781-793$.
38 Smith ZE, Higgs DR: The pattern of replication at a human telomeric region (16p13.3): its relationship to chromosome structure and gene expression. Hum Mol Genet 1999; 8: 1373 1386.

39 Huisman THJ, Carver MFH, Efremov GD: A Syllabus of Human Hemoglobin Variants. The Sickle Cell Anemia Foundation. Augusta, GA, USA, 1996.

40 Kikuchi A: Roles of Axin in the Wnt signalling pathway. Cell Signal 1999; 11: $777-788$

41 Greenspan RJ, O'Brien MC: Genetic analysis of mutations at the fused locus in the mouse. Proc Natl Acad Sci USA 1986; 83: 44134417.

42 Ruvinsky AO, Agulnik AI: Gametic imprinting and the manifestation of the Fused gene in the house mouse. Dev Genet 1990; 11: 263-269.

43 Wilkie AOM, Higgs DR, Rack KA et al. Stable length polymorphism of up to $260 \mathrm{~kb}$ at the tip of the short arm of human chromosome 16. Cell 1991; 64: 595-606.

44 Flint J, Craddock CF, Villegas A et al: Healing of broken human chromosomes by the addition of telomeric repeats. Am J Hum Genet 1994; 55: 505-512.

45 Rüdiger NS, Gregersen N, Kielland-Brandt MC: One short well conserved region of Alu-sequences is involved in human gene rearrangements and has homology with prokaryotic chi. Nucleic Acids Res 1995; 23: 256-260.

46 Harteveld CL, Losekoot M, Fodde R, Giordano PC, Bernini LF: The involvement of Alu repeats in recombination events at the $\alpha$-globin gene cluster: characterization of two $\alpha^{\mathrm{o}}$-thalassemia deletion breakpoints. Hum Genet 1997; 99: 528-534.

47 Snow BE, Krumins AM, Brothers GM et al: A G protein gamma subunit-like domain shared between RGS11 and other RGS proteins specifies binding to Gbeta5 subunits. Proc Natl Acad Sci USA 1998; 95: $13307-13312$.

48 Harris PC, Barton NJ, Higgs DR, Reeders ST, Wilkie AOM: A long range restriction map between the $\alpha$-globin complex and a marker closely linked to the polycystic kidney disease I (PKDI) locus. Genomics 1990; 7: 195-206.

49 Waye JS, Eng B, Chui DHK: Identification of an extensive $\zeta-\alpha$ globin gene deletion in a Chinese individual. $\mathrm{Br} J$ Haematol 1992; 80: $378-380$.

50 Higgs DR, Vickers MA, Wilkie AOM, Pretorius I-M, Jarman AP, Weatherall DJ: A review of the molecular genetics of the human $\alpha$-globin gene cluster. Blood 1989; 73: 1081-1104.

51 Hatton C, Wilkie AOM, Drysdale HC et al: Alpha thalassemia caused by a large $(62 \mathrm{~kb})$ deletion upstream of the human $\alpha$ globin gene cluster. Blood 1990; 76: $221-227$.

52 Craddock CF, Vyas P, Sharpe JA, Ayyub H, Wood WG, Higgs DR: Contrasting effects of $\alpha$ and $\beta$ globin regulatory elements on chromatin structure may be related to their different chromosomal environments. EMBO J 1995; 14: 1718 - 1726.

53 Liebhaber SA, Griese EU, Weiss I et al: Inactivation of human $\alpha$ globin gene expression by a de novo deletion located upstream of the $\alpha$-globin gene cluster. Proc Natl Acad Sci USA 1990; 81: 9431 9435.

54 Romao L, Cash F, Weiss I et al: Human $\alpha$-globin gene expression is silenced by terminal truncation of chromosome $16 \mathrm{p}$ beginning immediately $3^{\prime}$ of the $\zeta$-globin gene. Hum Genet 1992; 89: $323-328$.

55 Romao L, OsorioAlmeida L, Higgs DR, Lavinha J, Liebhaber SA: $\alpha$-thalassemia resulting from deletion of regulatory sequences far upstream of the $\alpha$-globin structural genes. Blood 1991; 78 : $1589-1595$.

56 Wilkie AOM, Lamb J, Harris PC, Finney RD, Higgs DR: A truncated human chromosome 16 associated with $\alpha$ thalassaemia is stabilized by addition of telomeric repeat (TTAGGG) . Nature 1990; 346: 868-871. 